\title{
On the Prevalence of Smooth Polymorphs at the Nanoscale: Implications for Pharmaceuticals
}

DOI:

10.1039/C8CE02098A

Document Version

Accepted author manuscript

Link to publication record in Manchester Research Explorer

\section{Citation for published version (APA):}

Belenguer, A. M., Cruz-cabeza, A. J., Lampronti, G. I., \& Sanders, J. K. M. (2019). On the Prevalence of Smooth Polymorphs at the Nanoscale: Implications for Pharmaceuticals. CrystEngComm.

https://doi.org/10.1039/C8CE02098A

\section{Published in:}

CrystEngComm

\section{Citing this paper}

Please note that where the full-text provided on Manchester Research Explorer is the Author Accepted Manuscript or Proof version this may differ from the final Published version. If citing, it is advised that you check and use the publisher's definitive version.

\section{General rights}

Copyright and moral rights for the publications made accessible in the Research Explorer are retained by the authors and/or other copyright owners and it is a condition of accessing publications that users recognise and abide by the legal requirements associated with these rights.

\section{Takedown policy}

If you believe that this document breaches copyright please refer to the University of Manchester's Takedown Procedures [http://man.ac.uk/04Y6Bo] or contact uml.scholarlycommunications@manchester.ac.uk providing relevant details, so we can investigate your claim.

\section{OPEN ACCESS}




\title{
Journal Name
}

\section{ARTICLE}

\section{On the Prevalence of Smooth Polymorphs at the Nanoscale: Implications for Pharmaceuticals}

Received 00th January 20xx, Accepted 00th January 20xx DOI: $10.1039 / x 0 \times x 00000 x$ www.rsc.org/

\begin{abstract}
Ana M. Belenguer ${ }^{1 *}$, Aurora J. Cruz-Cabeza ${ }^{2,3^{*}}$, Giulio I. Lampronti ${ }^{1,4^{*}}$ and Jeremy K. M. Sanders ${ }^{1 *}$
We demonstrate, for four different systems of pharmaceutical relevance, that ball mill grinding leads to different polymorphic transformations dependending on the milling conditions. In all four cases, the commercial polymorph converts to a different polymorph upon ball-mill neat grinding (NG). This transformation can be reversed by grinding the so obtained polymorph in the presence of small amounts of solvent (LAG), leading back to the commercial polymorph. Scherrer particle size determinations reveal that NG conditions almost always lead to smaller particle sizes in the nanometer length scales. Computational studies confirm that polymorphs obtained by the specific ball mill LAG conditions reported correspond to the the lowest lattice energy forms. Our study further confirms our earlier conclusions that, at the nanoscale, polymorphs with higher lattice energies can become the thermodynamically stable forms if their surfaces are more stable than those of the polymorphs obtained by LAG. We found, however, one exception to this trend in D-sorbitol. We observe that polymorphs with smoother surfaces (low roughness) are usually the ones observed by NG. This observation points to a link between surface roughness and surface stability.
\end{abstract}

\section{Introduction}

We recently demonstrated ${ }^{1-3}$ that relative thermodynamic stabilities of crystal polymorphs can be reversed upon ball mill grinding by carefully controlling the milling conditions, i.e. neat grinding (NG) vs liquid assisted grinding under controlled amounts of solvent (LAG). This effect was explored thoroughly for two different polymorphic systems: a single component aromatic compound ${ }^{1}$ and a cocrystal ${ }^{1,3}$. In both cases, the most stable polymorph under normal crystallisation conditions converted to a different polymorph upon ball mill NG. LAG in the presence of solvents above a critical amount reversed the transformation back towards the polymorph stable under ambient conditions. We found that these transformations are driven by thermodynamics: the experiments always result in the most stable polymorph but, at nanometer

\footnotetext{
${ }^{1}$ Department of Chemistry, University of Cambridge, Lensfield Road, Cambridge CB2 1EW, UK

${ }^{2}$ School of Chemical Engineering and Analytical Science, The University of Manchester, Oxford Road, Manchester, UK, M13 9PL, UK

${ }^{3}$ Astra Zeneca, Silk Road Business Park, Charter Way, Macclesfield, SK10 2NA, United Kingdom

${ }^{4}$ Department of Earth Sciences, University of Cambridge, Downing Street, Cambridge CB2 3EQ, UK

+Corresponding authors: amb84@cam.ac.uk, JKMS@cam.ac.uk,

aurora.cruzcabeza@manchester.ac.uk; gil21@cam.ac.uk

Electronic Supplementary Information (ESI) available: Detailed procedure for the polymorph interconversion turnover experiments, PXRD patterns, data and estimated crystal size by whole pattern Rietveld and Pawley refinements and SEM See DOI: $10.1039 / x 0 x x 00000 x$
}

length scales, the relative stability of polymorphs changes as a function of size, and the milling conditions affect the overall average crystal size and stability of crystallites. ${ }^{1,3}$

At the nanoscale, surface effects become sufficiently significant to affect the thermodynamic stability of crystal forms. $^{4}{ }^{5}$ Results from nanoscale confinement ${ }^{6}$ and confinement in inkjet printed droplets ${ }^{7}$ are consistent with this observation. Thus, the overall thermodynamic stability of the nanocrystal depends not only on the stability of the bulk crystal but also on the stability of the surfaces exposed by milling. Surface stabilities are obviously closely related to their structure but they are also affected by the nature and concentration of solvent adsorbed onto them. ${ }^{1,3}$ The thermodynamic aspects of these transformations must be general and must apply to any milling system, independent of the nature of the chemical or supramolecular bonds involved in the transformation studied, as long as a metastable-bulk polymorph with more stable surfaces exists and the higher energy of the lattice can be compensated by the relatively lower energy of the surfaces. Thus, we expect this phenomenon to be common in the polymorphism of pharmaceuticals, as reported here.

Various authors have reported polymorph "turnover phenomena" under milling conditions for a number of molecular compounds: the conversion from one polymorph to a different one by ball mill NG and from the latter to the first polymorph by ball mill LAG. ${ }^{1,8-11}$ Such transformations suggest that the polymorph stability order can be reversed under milling conditions. In a sealed jar, after the 
completion of the milling reaction, an equilibrium is reached with a phase composition that does not change as long as the milling conditions are maintained. ${ }^{1,12-15}$ For some compounds it has been proved that the polymorph obtained under ball mill NG conditions does not depend on the starting polymorph, e.g. phenylbutazone ( $\delta$ is obtained from either $\alpha$ or $\beta$ ), ${ }^{16}$ D-mannitol ( $\alpha$ is obtained from either $\beta$ or $\gamma$ ), ${ }^{17,18}$ modafinil (form III is obtained from form I, III , IV, V or VI), ${ }^{10}$ sulfathiazole (form I starting from form I, II, III, IV or V.). ${ }^{19}$ However, for some other compounds the polymorph produced under NG is dependent on the starting polymorph: it has been reported that in the case of anthranilic acid upon ball mill NG, : pure form I gives form III, pure form III does not change and pure form II does not change. ${ }^{11}$ Our interpretation is that these latter cases do not represent milling equilibria but rather intermediate kinetic points. If the milling experiment is stopped before the milling equilibrium is achieved, the product obtained can be affected by kinetics. Unfortunately, in most studies on polymorph transformation by milling, only one or very few milling times are tested. Indeed kinetic studies are necessary to detect equilibria in milling reactions: milling thermodynamic equilibria depend on numerous factors, including in particular the LAG solvent concentration, ${ }^{1,3}$ as well as solvent nature. In the case of sulfathiazole, form I transforms into different polymorphs depending on the solvent used: ; form III with water or methanol; form IV with ethanol, n-propanol, isopropanol, ethyl acetate, acetonitrile, heptane or hexane - these ball mill LAG experiments with sulfathiazole were all run for 30 minutes only, so they could either represent equilibria or kinetic results. ${ }^{19}$

We have searched the relevant published literature ${ }^{20-22}$ in order to identify polymorphic transformations of compounds of pharmaceutical interest upon milling that may be a result of crystal size changes. We selected four single component polymorphic systems of pharmaceutical interest: (i) caffeine (caf), ${ }^{23}$ (ii) D-sorbitol (d-sor), ${ }^{17,}{ }^{24}$ (iii) chlorpropamide (cpa) $)^{25}$ and (iv) N-acetyl-L-phenylalanine amide (apaa) $)^{8}$. There is evidence for $\mathrm{caf}^{23}, \mathrm{D}-$ sor $^{624}$ and $\mathrm{apaa}^{8}$ that the thermodynamically stable polymorph under ambient conditions transforms into a different polymorph under ball mill NG. For apaa, additionally, it is known that LAG with water converts the polymorph obtained by NG back to the thermodynamically stable form under ambient conditions. Finally, the polymorphism of cpa has been widely studied since it is one of the richest polymorphic compounds known. For example, a range of mechanical processes (shear and impact treatments) have been used to explore phase transitions between polymorphs of $\mathrm{cpa} .{ }^{25}$

In this contribution, we have further explored the milling induced polymorphic transformations for the four systems above. For each system, a full set of polymorph turnover experiments under ball mill conditions was carried out (Scheme 1). These experiments consist of: a polymorph conversion by ball mill NG; the reverse transformation upon specific ball mill LAG conditions. These transformations are repeated several times to prove the reversibility of the process upon adjustment of the milling conditions (Figure 1). To further advance our understanding of thermodynamics of the process, we have also, when possible, computed the relative lattice energies of the polymorphic forms involved in these transformations. Further to this, we present a structural analysis of the dominant crystal surfaces of these polymorphs. Table 1 lists relevant details for all the polymorphs studied in the present work.

Table 1 Polymorphs studied in this work and their relevant details. For all systems, the form obtained under the specific LAG conditions used corresponds to the commercially available form.

\begin{tabular}{|c|c|c|c|c|c|c|}
\hline \multicolumn{2}{|c|}{ System } & \multicolumn{3}{|c|}{ LAG Conditions } & \multicolumn{2}{|c|}{$\begin{array}{l}\text { Form obtained } \\
\text { after grinding* }\end{array}$} \\
\hline Name & Abb. & $\begin{array}{l}\text { Solid } \\
\text { (mg) }\end{array}$ & $\begin{array}{c}\text { Solvent } \\
(\mu \mathrm{L})\end{array}$ & $\begin{array}{l}\text { Solvent } \\
\text { Nature }\end{array}$ & LAG & NG \\
\hline caffeine $^{23}$ & caf & 300 & 50 & $\mathrm{MeCN}$ & $\begin{array}{c}\text { Form } \\
\|\|^{\S}\end{array}$ & $\begin{array}{c}\text { Form } \\
\text { III" }^{\pi}\end{array}$ \\
\hline${ }_{24}^{\text {D-sorbitol }^{17,}}$ & D-sor & 300 & 50 & $\mathrm{MeCN}$ & $\underset{\S}{\text { Form } \gamma}$ & $\begin{array}{c}\text { Form } \\
\alpha^{\S}\end{array}$ \\
\hline $\begin{array}{c}\text { Chlorpropa } \\
\text { mide }^{25}\end{array}$ & сра & 300 & 50 & $\mathrm{MeCN}$ & $\begin{array}{l}\text { Form } \\
\beta^{\S}\end{array}$ & $\begin{array}{c}\text { Form } \\
\eta^{\natural}\end{array}$ \\
\hline $\begin{array}{l}\mathrm{N} \text {-acetyl-1- } \\
\text { phenylalani } \\
\text { ne amide }\end{array}$ & apaa & 300 & 100 & $\mathrm{H}_{2} \mathrm{O}$ & $\begin{array}{c}\text { Form } \\
\gamma^{\S}\end{array}$ & $\begin{array}{c}\text { Form } \\
\alpha^{\S}\end{array}$ \\
\hline
\end{tabular}

* Not all forms obtained by grinding correspond to structures reported in the CSD. Forms previously known and reported in the CSD are indicated by the $\S$ whilst new forms are indicated by ". Further details including CSD refcodes and new PXRD patters are given in the ESI and in Table 2.

** New form. Details about the pattern indexing and space group statistics are reported in the $\mathrm{SI}$.

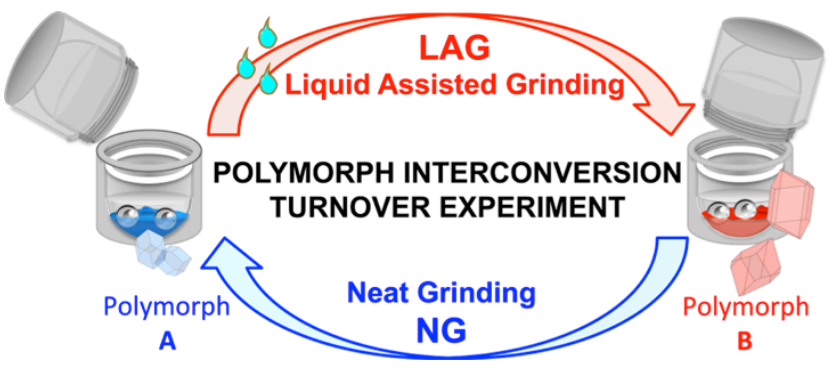

Scheme 1 Polymorph turnover experiments in which polymorphs are reversibly interconverted upon ball mill grinding under neat and wet conditions.

\section{Experimental Section}

Polymorph turnover experiments. Polymorph conversions by ball mill NG

$300 \mathrm{mg}$ of the commercially available form (which for all four systems corresponds to the form obtained under the specific ball mill LAG conditions reported below) of anhydrous caf, D-sor, cpa or apaa were added to a $14.5 \mathrm{~mL}$ stainless steel screw-closure milling jar together with two 7 $\mathrm{mm}$ diameter stainless steel ball bearings with no added 
solvent. The jars were carefully sealed and milling was performed at $30 \mathrm{~Hz}$ on a MM400 Retsch automated grinder at ambient temperature The materials were ball mill NG at $30 \mathrm{~Hz}$ for the time indicated in Figure 1. Grinding times for NG were based on the corresponding publications. ${ }^{8,23-25}$ In some cases grinding had to be performed for extensive periods of time up to $8 \mathrm{~h}$. The ball mill grinder was programmed to achieve the total grinding times in consecutive 60 minute runs separated by 5 minute intervals to avoid the jar from warming and to allow the grinding motor to rest. The grinder shielding was removed and replaced with an external safety shield in order to prevent the ventilation system of the motor from heating the milling jar over prolonged milling times. Immediately after completion of each grinding experiment, jars were opened and samples were immediately analysed using PXRD and specimens were taken for scanning electron microscopy (SEM). while more details are reported in the ESI.

\section{Polymorph conversions by ball mill LAG}

To quantitatively convert the polymorphs obtained by ball mill NG of anhydrous caf, D-sor, and cpa from the in-situ NG-polymorph (300 $\mathrm{mg}$ payload) back to the commercially available polymorph, $50 \mu \mathrm{L} \mathrm{MeCN}$ were added to the milling jar and the material was subjected to ball mill LAG at $30 \mathrm{~Hz}$ for the period shown in Figure $1 \mathrm{a}, 1 \mathrm{~b}$ and $1 \mathrm{c}$ respectively. To prepare the commercially available polymorph of $\mathrm{N}$ acetyl-L-phenylalanine amide, $100 \mu \mathrm{L}$ water were added to the jar and the material was subjected to ball LAG at $30 \mathrm{~Hz}$ for the period of time shown in Figure 1d. Powders recovered from ball mill LAG experiments had to be dried before performing a new in situ NG experiment in order to remove the residual solvents, sometime requiring the open jar to be left in a desiccator containing dry Drierite desiccants, overnight.

The experimental conditions for the four turnover experiments (transformation of the commercially available form by ball mill NG, and polymorph conversion back to the commercially available form by the specific ball mill LAG conditions reported) for each of the four systems discussed here are shown in Figure 1 and more extensively explained in ESI, Section 2.1. When necessary, a method had to be developed for the polymorph interconversion (See ESI, Section 3). The careful methodology we use for ball mill grinding experiments has been published elsewhere. ${ }^{2}$

\section{Powders characterisations.}

The powders were analysed by powder X-ray diffraction (PXRD), and specimens were gold-coated for scanning electron microscopy (SEM) immediately after completion of the grinding experiment.

\section{Scanning Electron Microscopy (SEM)}

SEM secondary electron analyses were performed on a FEI Quanta650F instrument operating at an acceleration voltage of 2 to $3 \mathrm{kV}$ (spot size 1 to 2). Milled powder specimens were sprinkled through a mesh on a conductive tape on top of an aluminum stub and were gold coated for the analysis. A selection of SEM images is reported in the ESI.

\section{Powder X-ray Diffraction (PXRD)}

$\mathrm{X}$-ray powder diffractograms in the $2 \vartheta$ range $5-45^{\circ}$ ( $\mathrm{Cu} \mathrm{K \alpha}$ radiation, step size $0.03^{\circ}$, time/step $100 \mathrm{~s}, 0.04$ rad soller, VxA 40x40 with a total time of 13 minutes) were collected on a Panalytical X'Pert Pro diffractometer equipped with an $X^{\prime}$ Celerator detector operating in reflection geometry. Glass PXRD sample slide $(10 \times 15 \mathrm{~mm})$ with the $2 \mathrm{~mm}$ rectangular recess were used to load the samples.

Indexing of the NG-polymorph of caf and cpa was performed with the algorithm DICVOL $^{26}$ included in the software DASH v3.3.6. ${ }^{27}$ Details about the indexing analysis are reported in the ESI.

Rietveld and Pawley refinements were performed with the software Topas V6. ${ }^{28}$ Details about the refinements setup are given in the ESI. $R_{w p}$ and $\chi^{2}$ values, ranging typically from $9 \%$ to $15 \%$ and from 1 to 4 respectively, are reported for all refinements in the ESI.

The crystal size was estimated by whole pattern Rietveld refinements (or alternatively by structureless Pawley refinements in the cases where the crystal structure model was missing) which incorporate the Scherrer equation,

$$
\text { crystal size }[\text { in } \mathrm{nm}]=k \lambda /(10 \cdot \Delta \vartheta \cdot \cos \vartheta),
$$

where $k$ is a crystal shape factor most often assumed to be $0.9, \lambda$ is the radiation wavelength and $\vartheta$ is the diffraction angle, into the peak shape function in a given crystallographic direction $(h k l)$ according to the following equation:

$$
\text { fwhm }(2 \vartheta, h k l)=\lambda /(\cos \vartheta \cdot \text { crystal size }[\text { in } \mathrm{nm}]),
$$

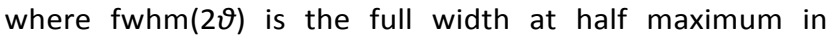
radians of the peak at a given diffraction angle and a given crystallographic direction. ${ }^{29}$ The $\mathrm{LaB}_{6} 660 \mathrm{~b}$ NIST standard ${ }^{30}$ was used to model the instrumental contribution to peak broadening using a fundamental parameters approach. ${ }^{31}$

Retrieval of crystal structure information and visualisations.

Available crystal structure data for the systems studied here were retrieved from the Cambridge Structural Database (vs. 5.39) ${ }^{32}$ using Conquest. Crystal structures and surfaces were then visualised with the aid of Mercury vs. $3.10^{33}$

\section{Calculations of relative lattice energies.}

Crystal structures retrieved from the CSD were optimised with periodic DFT with van der Waals corrections. The PBE functional $^{34}$ was used with PAW pseudopotentials ${ }^{35,36}$ and the Grimme's van der Waals corrections $(\mathrm{d} 2)^{37}$ as implemented in the VASP code (version 5.4). ${ }^{38-41}$ An energy cut off of $520 \mathrm{eV}$ was used for the planewaves. The Brillouin zone was sampled using the Monkhorst-Pack approximation $^{42}$ at k-point grids separated by approximately $0.05 \AA$ A. A first optimisation was carried out allowing the unit cell parameters and atomic positions to change, followed by a second optimisation of atomic 
positions with fixed unit cell parameters. Geometry optimisations were stopped when the calculated force on every atom was less than $0.003 \mathrm{eV} \AA^{-1}$. Computed electronic energies were normalised by the number of molecules in the simulation cell. Lattice energies were then calculated relative to the most stable polymorph $\left(\Delta \mathrm{E}_{\text {latt }}\right)$ by subtracting the normalised electronic energy of the most stable polymorph from that of the polymorph under study.

\section{BFDH Morphologies.}

BFDH (Bravais Friedel Donnay Harker) morphologies ${ }^{43}$ were calculated from the CSD crystal structures using the BFDH morphology calculator implemented in the Materials Module in Mercury.

\section{Calculation of rugosity depth.}

The slicing functionality of Mercury was used to display the surfaces of interest. Then, a plane was defined containing the atoms of maximum height on that surface (highest plane). The distance between the lowest height accessible atom on the surface and the highest plane was then calculated. This parameter is defined as the rugosity depth parameter.

\section{Results and discussion}

\section{Polymorph Turnover Experiments}

We performed polymorph turnover experiments (Figure 1) for the four pharmaceuticals: caf, d-sor, cpa and apaa. In all these four systems, NG of the commercially available form leads to a different polymorph, the NG-polymorph. LAG on the NG-polymorph reversed the transformation and leads back to the original commercially available form, the LAGpolymorph (Figure 1). This process is reversible in all these cases. With the exception of the last compound, we used acetonitrile (MeCN) for our LAG experiments in a stoichiometric proportion of $50 \mu \mathrm{L}: 300 \mathrm{mg}$ of solid material. ${ }^{1,}$

${ }^{3}$ Other solvents would be also be expected to lead to these results though different stoichiometric proportions may be required. ${ }^{1-3}$ For our last compound, the LAG was done with water to match the LAG conditions reported in the literature. ${ }^{8}$ We highlight that milling time is also an important factor: our milling experiments are carried out until we observe no further change in the XRD patterns of our powders.

\section{Polymorphs of caffeine and chlorpropamide obtained by NG}

In the course of these experiments, we noticed that the polymorphs obtained by NG for caf and CPA have PXRD patterns which do not exactly match expectations for published crystal structure models.

The caffeine NG-polymorph has been reported to have an unknown crystal structure. ${ }^{23}$ Indeed neither form I nor form II of caf are consistent with our powder pattern. The same is true for chlorpropamide. For these two systems we have found a unit cell and space group (see ESI) and have used them to estimate the Scherrer size from diffraction peak broadening. We are currently further investigating these two systems in the hope of obtaining a correct structural model. Because of this, however, we could not use caf or cpa for our modelling in the sections below.

\section{Polymorphs by LAG vs. Polymorphs by NG: lattice stabilities (bulk)}

Our previous experience with milling experiments led to the conclusion that polymorphs obtained by LAG are often stable-bulk polymorphs whilst the generally-smaller crystals of NG-polymorphs are metastable bulk forms with more stable surfaces $.1,3,13$ In an attempt to understand this effect in a wider set of compounds, we computed the relative lattice energies of interconverting polymorphic pairs. For this exercise, we used the new experimental data reported here for $d$-sor and apaa, our previous well studied ncps system and two other systems previously reported by Trask et al. ${ }^{11}$-anthranilic acid (aa, also studied by Ojala and Etter $^{44}$ ) and succinic acid (sa)- (Table 2). The lattice energies relative to the most stable form of these polymorphs were computed using periodic DFT-d with VASP as described in the methods section. This is one of the most accurate models for computing relative stabilities of polymorphic forms currently available. ${ }^{45}$

The results in Table 2 show that in all systems with the exception of $d$-sor, the polymorph obtained under the specific ball mill LAG conditions used is the most stable bulk polymorph. The lattice energy differences between polymorphs of ncps, aa and sa are less than $1.5 \mathrm{~kJ} / \mathrm{mol}$. This small lattice energy difference may be off-set by small changes in surface stabilities between the polymorphs at the nanoscale. For aapa, the lattice energy difference between the LAG and NG form is larger, $5.5 \mathrm{~kJ} / \mathrm{mol}$. We notice, however, that the NG polymorphs of this system contain disorder in the structure. This disorder was not modelled in our computations but it will likely lower the free energy differences between the forms. For D-Sor, form $\gamma$ (GLUCITO3) obtained by LAG, was calculated to be 9.5 $\mathrm{kJ} / \mathrm{mol}$ less stable than the polymorph obtained by NG (form $\alpha$ ) and form $\varepsilon$. We notice, however, that form $\gamma$ of $D$ sor (the LAG-polymorph) is known to be the thermodynamically stable form at large crystal sizes. ${ }^{24}$ We also notice that the structure of form $\gamma$ was solved from powder X-ray diffraction. Thus, it is possible that the position of hydrogen atoms may not be sufficiently accurate for our computational model. D-sor has six hydroxyl groups and wrong placements on the $\mathrm{H}$ atom positions of these hydroxyl groups may impact the overall computed relative lattice energy of the structure. 


\section{Journal Name}

\section{ARTICLE}<smiles>Cn1c(=O)c2c(ncn2C)n(C)c1=O</smiles>

a)

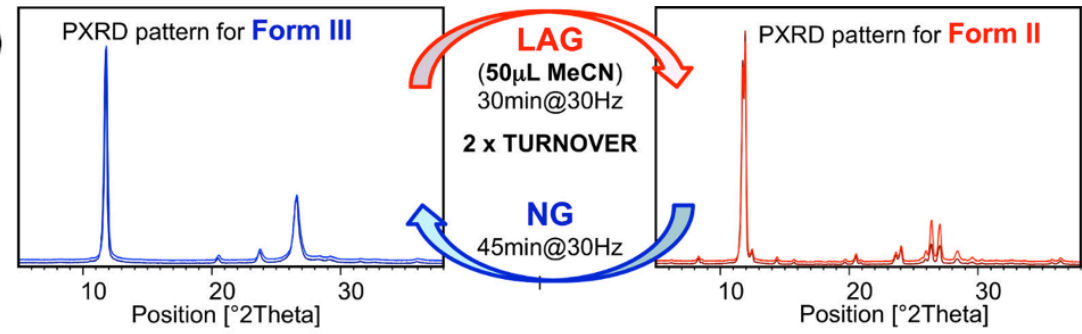

caf, $300 \mathrm{mg}$
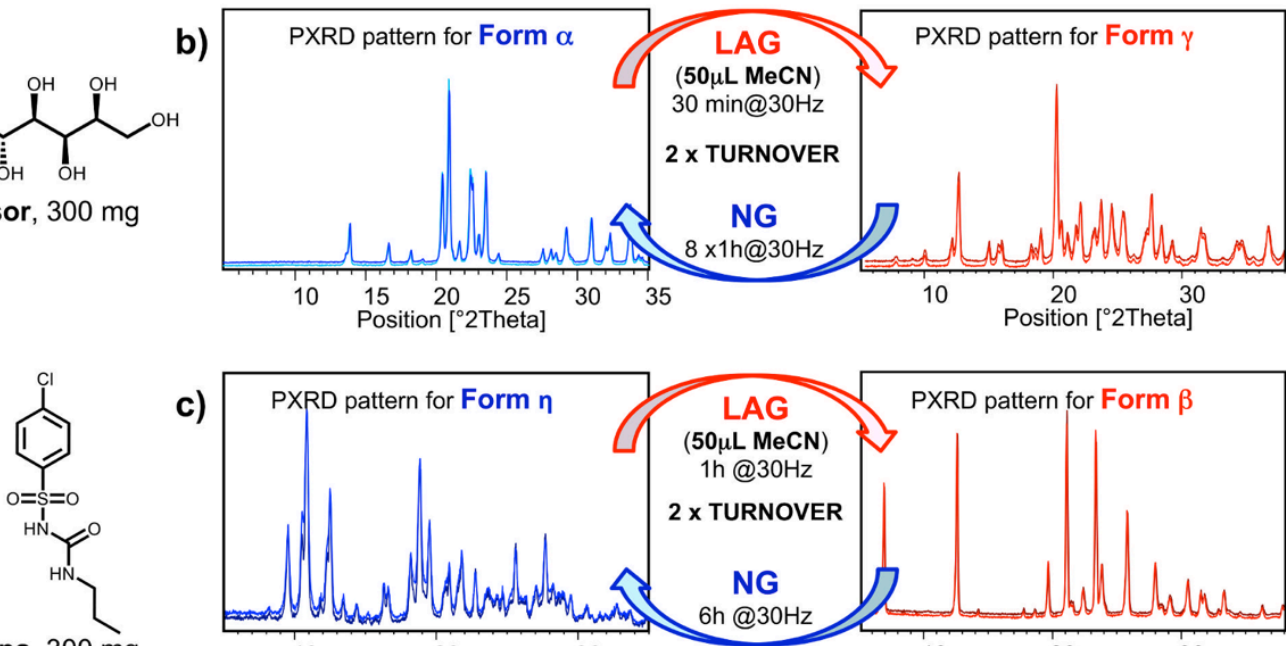

c)

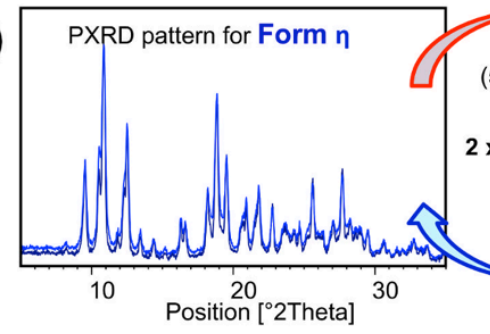

LAG (50 $\mu \mathrm{L} \mathrm{MeCN)}$

1h @30Hz

$2 \times$ TURNOVER

NG

6h@30Hz

cpa, $300 \mathrm{mg}$

d)

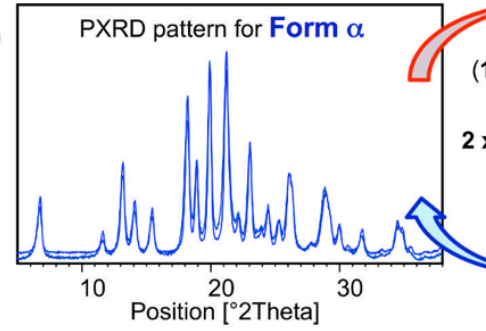

LAG

$100 \mu \mathrm{L}$ water

$1 \mathrm{~h} @ 30 \mathrm{~Hz}$<smiles>C=C(N)C(Cc1ccccc1)NC(C)=O</smiles>

$2 \times$ TURNOVER

NG

8h @ $30 \mathrm{~Hz}$

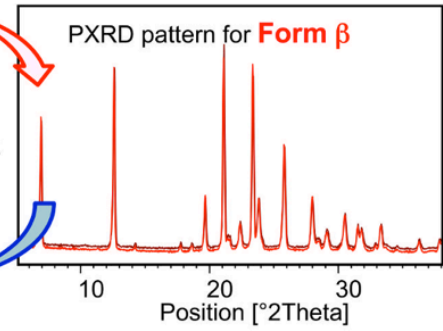

apaa, $300 \mathrm{mg}$

e)

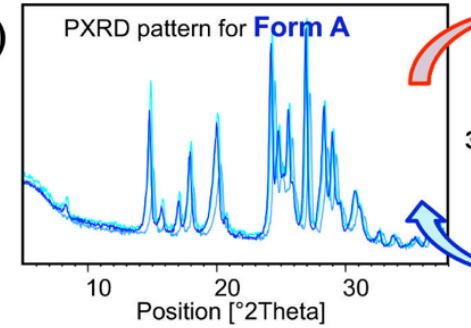

LAG $(50 \mu \mathrm{L} \mathrm{MeCN})$ 30min@30Hz<smiles>O=[N+]([O-])c1ccccc1SSc1ccc(Cl)cc1</smiles>

ncps, $250 \mathrm{mg}$ $3 \times$ TURNOVER

NG 150min@30H

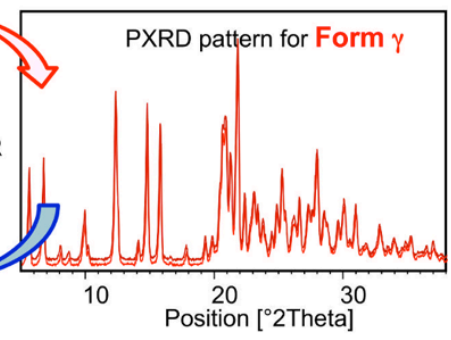

igure 1 Demonstration of reversible transformation of bulk stable polymorphs into metastable polymorphs under neat grinding, and the reverse under LAG grinding conditions. Anhydrous Caffeine (caf); D-Sorbitol (D-sor); Chlorpropamide (CPA); Acetyl-L-Phenylalanine amide (apaa) and 2-nitrophenyl-4-chlorophenyl-disulfide (ncps) ${ }^{1,13}$. PXRDs for bulkmetastable polymorphs are shown on the left in blue while PXRDs for the bulk-stable polymorph are shown on the right in red. 
Table 2. Set of polymorphic systems which interconvert upon changing the milling conditions (polymorphs other than those obtained by grinding are also presented): computed relative lattice energies $\left(\Delta \mathrm{E}_{\mathrm{Latt}}\right)$, summary of the dominant surfaces expected, their morphological importance (MI) and the calculated rugosity depth parameter (RDepth). The main surface for each polymorph is identified making use of the BFDH morphology prediction method

\begin{tabular}{|c|c|c|c|c|c|c|c|c|}
\hline Abb. & Name & Grinding Conditions & $\begin{array}{c}\text { CSD } \\
\text { Refcode }\end{array}$ & Form & $\begin{array}{c}\Delta \mathrm{E}_{\text {Latt }} \\
(\mathrm{kJ} / \mathrm{mol})\end{array}$ & $\begin{array}{c}\text { Main BFDH } \\
\text { Surfaces }\end{array}$ & $\begin{array}{l}\text { BFDH } \\
\text { MI }^{\mathscr{B}}\end{array}$ & $\begin{array}{c}\mathbf{R}_{\text {depth }} \\
\text { (Å) }\end{array}$ \\
\hline \multirow{3}{*}{ D-sor } & \multirow{3}{*}{ D-Sorbitol } & LAG (300 mg:50 $\mu \mathrm{L} \mathrm{MeCN})$ & GLUCIT03 & $\gamma$ & 9.5 & $\left\{\begin{array}{lll}1 & 1 & 0\end{array}\right\}$ & $76 \%$ & 4.0 \\
\hline & & - & GLUCIT02 & $\varepsilon$ & 0.0 & $\left\{\begin{array}{lll}0 & 0 & 1\end{array}\right\}$ & $52 \%$ & 1.7 \\
\hline & & NG & CLUCIT01 & $\alpha$ & 0.0 & $\left\{\begin{array}{lll}0 & 1 & 1\end{array}\right\}$ & $40 \%$ & 1.7 \\
\hline \multirow{3}{*}{ apaa } & \multirow{3}{*}{$\begin{array}{l}\mathrm{N} \text {-acetyl phenyl } \\
\text { alanine amide }\end{array}$} & LAG (300 mg:100 $\mu \mathrm{L}$ water) & KINSILO4 & $\gamma$ & 0.0 & $\left\{\begin{array}{lll}2 & 0 & 0\end{array}\right\}^{*}$ & $34 \%$ & 4.7 \\
\hline & & NG & $\mathrm{KINSIL}^{\S}$ & $\alpha$ & 5.5 & $\left\{\begin{array}{llll}0 & 1 & 1\end{array}\right\}^{*}$ & $34 \%$ & 4.2 \\
\hline & & - & $\mathrm{KINSILO}^{\S}$ & $\beta$ & 5.9 & $\left\{\begin{array}{lll}1 & 0 & 0\end{array}\right\}^{*}$ & $34 \%$ & 5.3 \\
\hline \multirow[b]{2}{*}{ ncps } & \multirow{2}{*}{$\begin{array}{l}\text { 2-nitrophenyl- } \\
\text { 4-chorophenyl } \\
\text { disulfide }\end{array}$} & LAG (250 mg:50 $\mu \mathrm{L} \mathrm{MeCN})^{1,9}$ & FUQLIM & Form B & 0.0 & $\left\{\begin{array}{lll}0 & 0 & 1\end{array}\right\}$ & $39 \%$ & 6.3 \\
\hline & & NG & FUQLIM01 & Form A & 1.3 & $\left\{\begin{array}{ll}1 & 0-1\end{array}\right\}$ & $40 \%$ & 3.3 \\
\hline \multirow{3}{*}{ aa } & \multirow{3}{*}{ Anthralinic acid } & LAG (water) ${ }^{11, q}$ & AMBACO07 & Form I & 0.0 & $\left\{\begin{array}{lll}1 & 1 & 0\end{array}\right\}$ & $45 \%$ & 2.0 \\
\hline & & $\mathrm{NG}^{11}$ & AMBACO06 & Form III & 1.0 & $\left\{\begin{array}{lll}0 & 2 & 0\end{array}\right\}$ & $30 \%$ & 1.9 \\
\hline & & LAG (heptane) ${ }^{11, q}$ & AMBACO03 & Form II & 1.0 & $\left\{\begin{array}{lll}2 & 0 & 0\end{array}\right\}$ & $22 \%$ & 1.7 \\
\hline \multirow[t]{2}{*}{ sa } & \multirow[t]{2}{*}{ Succinic acid } & LAG (heptane) $)^{11,9}$ & SUCACB07 & $\alpha$ & 0.0 & $\left\{\begin{array}{lll}1 & 0 & 0\end{array}\right\}$ & $28 \%$ & 1.1 \\
\hline & & $\mathrm{NG}^{11}$ & SUCAB11 & $\beta$ & 0.7 & $\left\{\begin{array}{lll}1 & 0 & 0\end{array}\right\}$ & $24 \%$ & 1.0 \\
\hline
\end{tabular}

HBFDH MI = BFDH morphological importance (area of surface/area of the total morphology in \%). § Structures contain atomic disorder. १ Other LAG conditions also lead to this result. *Because the first dominant faces had very similar rugosity depths for all three forms ( 3.7), the second most important morphological surfaces were considered.

Finally, for sa, although the LAG forms in non polar solvents, the $\alpha$ form, was calculated to have the lowest lattice energy, it is believed that the experimentally stable form at larger sizes is the $\beta$ form. ${ }^{11}$ We notice, however, that the relative lattice energy computed for these forms is only $0.7 \mathrm{~kJ} / \mathrm{mol}$, within the limit of accuracy of the energy model.

In summary, the results in Table 2 further support the proposition that in these milling polymorphic transformations, the polymorph obtained under the specific ball mill LAG conditions here reported is the most stable bulk form (has the lowest lattice energy) and that the lattice energy difference between these polymorphs are very small.

\section{Polymorphs by LAG vs. polymorphs by NG: Surfaces}

In our previous work, computations showed that the NGpolymorph of ncps (form A) has the most stable surfaces, so as milling reduces the size of the crystals the relative stability of the polymorphs is switched on reaching a critical size. ${ }^{1}$ This is the reason as to why we see a different polymorph upon dry ball mill grinding. The calculations required to compute this switch in stability with size are difficult and computationally expensive. In an attempt to make predictions of the NG-polymorph more accessible, we have explored the concept of surface rugosity (roughness) and how this may be linked to surface stability. A molecule on a rough surface is deprived of many of the intermolecular interactions available to molecules on a smooth surface or within the bulk material and it is therefore expected to be is less stable. Using the BFDH model for morphology prediction ${ }^{43}$ we identified which surfaces are dominant in these polymorphs and their morphological importance (Table 2).

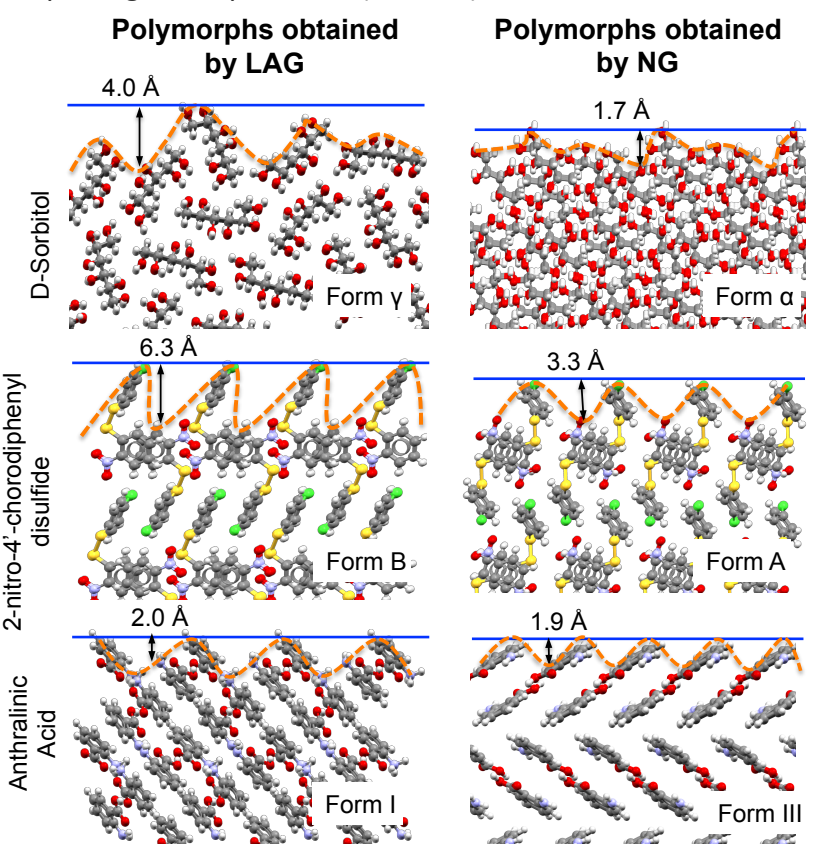


Figure 2 Illustration of the differences in rugosity for the dominant surfaces (BFDH model) of the polymorphs obtained by LAG vs those obtained by NG for Dsor, ncps and aa.

We then visualised these surfaces and realised that dominant surfaces in the stable bulk polymorphs obtained by LAG are generally rougher than dominant surfaces in metastable bulk polymorphs obtained by NG (Figure 2). To quantify this roughness, we calculated the rugosity depth parameter for all of these surfaces. This parameter is defined as the distance between the plane containing the highest positioned heavy atoms and the lowest accessible heavy atom on the surface of interest. A visual illustration of the roughness is given in Figure 2 for three systems whilst the roughness depth parameter is given for all systems in Table 2.

For the systems studied here, we notice that all metastable bulk polymorphs (obtained by NG) have smoother surfaces than their corresponding stable bulk polymorphs obtained by LAG (Table 2 ), i.e. smaller $R_{\text {Depth }}$. For some pairs of polymorphs (i.e. ncps or D-sor), the roughness difference is much more significant than for others (e.g. sa or aa). For the apaa polymorphs, the rugosity of the dominant faces was very similar in all cases, so the second most significant faces were then considered. In all cases, polymorphs obtained by NG have lower $\mathrm{R}_{\text {Depth }}$ than polymorphs by LAG (except for form II aa).

\section{Polymorphs by LAG vs. polymorphs by NG: Crystal Size}

To confirm that we are dealing with crystallites of dimensions smaller than hundreds of nanometers, we estimated the crystal size by whole pattern Rietveld and Pawley refinements of the collected powder patterns (Scherrer crystal size, see Figure 3 ). The powders were also characterised by SEM secondary electrons imaging (see ESI). For caf, cpa, apaa and ncps, the crystallites of the forms obtained by NG have average crystal sizes significantly smaller than the crystallites of the forms obtained by LAG. Interestingly for D-sor, we observe the opposite behaviour. Here the polymorph obtained by LAG (form $\gamma$ ) has crystallites significantly smaller in size than those obtained by NG (form $\alpha$, see ESI). We notice, that LAG polymorphs usually have crystal sizes over $100 \mathrm{~nm}$ in average size whilst the NG polymorphs usually have crystal sizes of $\sim 50 \mathrm{~nm}$ in size or less. In D-sor, the NG size is significantly larger of over $100 \mathrm{~nm}$ in size, while the size under ball mill LAG conditions is significantly smaller. We here remind that the measurements were made ex-situ and the crystallites may grow in the few minutes between the end of the experiment and the PXRD data collection - this crystal size change may be significant in this case. Furthermore, it is entirely possible that $\mathrm{MeCN}$ stabilises the surfaces of the bulk-stable polymorph, so that it becomes even more stable under LAG conditions with MeCN than the metastable bulk polymorph by decreasing the crystal size.

\section{Discussion}

While most of the literature about the fundamental science of mechanochemistry deals with the mechanisms of transformation under milling conditions, 14, 46-52 our research has focused on the final equilibria of ball mill grinding reactions and transformations. It is generally accepted that milling reactions show a terminal equilibrium with a phase composition that does not change when the milling time is increased. ${ }^{12,} 14,48$ Our ball mill thermodynamic experiments shown here for four pharmaceuticals prove that the polymorph stability order is reversed under NG conditions. The question is not whether the stabilities change but rather why they do so. Local variations in temperature ("hot spots") and pressure have been suggested to be essential to overcome the kinetic energy barriers of milling reactions and transformations. ${ }^{49}$, ${ }^{50}$ However, the change in polymorph stabilities can only be caused by one or more of the following factors: (a) the average temperature in the milling jar; (b) the average pressure in the milling jar; (c) any change in the bulk structure of crystallites subjected to the ball mill grinding process; (d) the contribution to the total free energy of the surface structure if the crystallites are reduced to dimensions smaller than hundreds of nanometers by the milling process, and the morphology of such nanocrystals; (e) the effect on the total free energy of solvent adsorption processes on the nanocrystal surfaces. While we do not exclude (a), (b) and (c), we have shown experimentally and computationally that crystal surface to volume ratios and surface related effects are likely to play the main role in polymorph stabilities under milling conditions. In this contribution, we have shown this effect for four systems of pharmaceutical interest. 

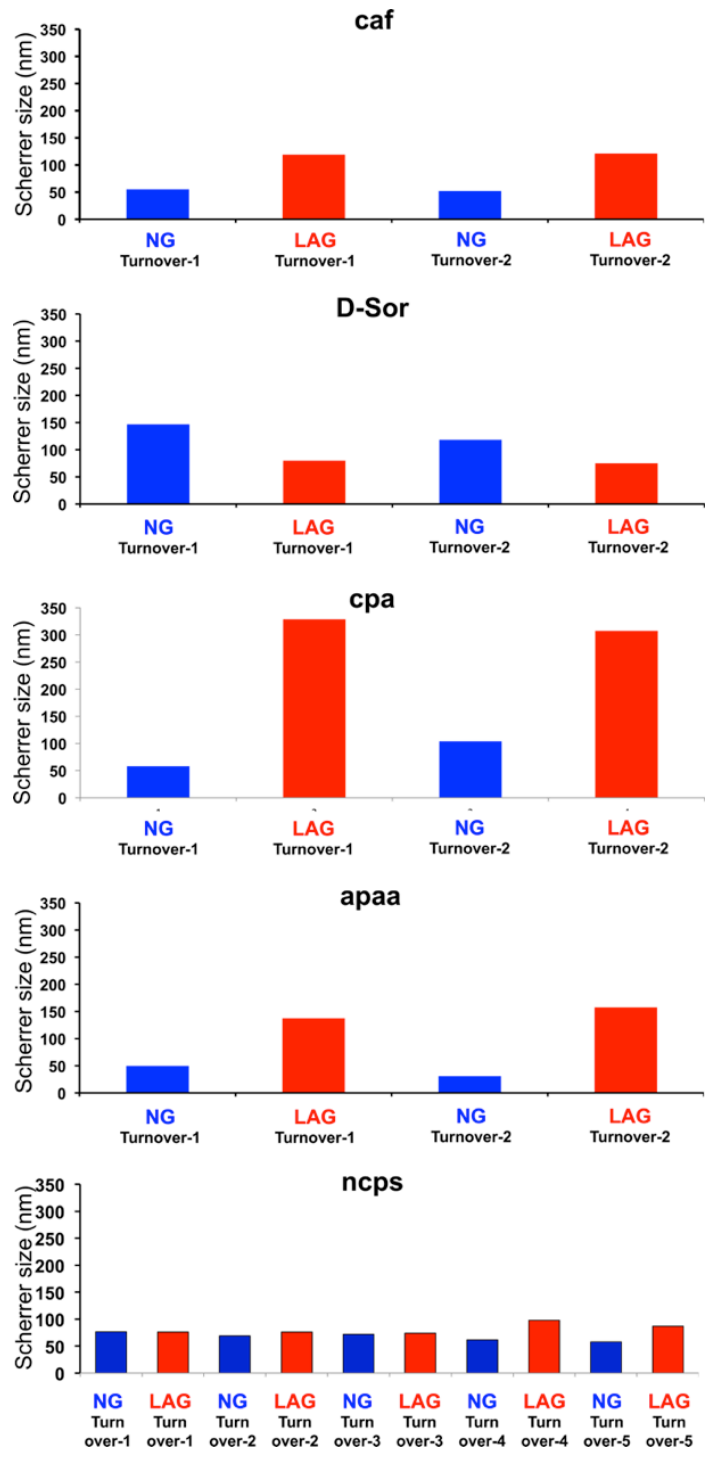

Figure 3 Scherrer size for nanocrystals obtained by NG and LAG, as estimated by Rietveld and Pawley refinements (see $\mathrm{SI}$ ). The e.s.d. is $5 \%$ relative or smaller for all sizes here reported (see SI)

For the systems in this study, we have shown several aspects with complementary computational and experimental techniques. Using experimentation, we have shown that (a) the transformations are reversible and always give the same products as long as the milling conditions are carefully kept constant and (b) that the particle size of NG conditions is usually smaller (with the exception of D-Sor). Using computations, we have shown that (a) the polymorph obtained by the specific ball mill LAG conditions used corresponds to the form with the lowest lattice energy, the stable-bulk polymorph and (b) that NG forms usually have smoother surfaces.

Thus, for the stability of the polymorphs to be reversed upon reduction of crystal size on NG, the metastable bulk polymorph must have surfaces that are relatively more stable. We have now made a link, for the first time, between surface stability and roughness. We have shown how polymorphs obtained by LAG usually have rougher (less stable) surfaces whilst polymorphs obtained by NG have smoother (more stable) surfaces. Our approach for roughness estimation has been driven by practicality. Whilst the morphology of a crystal involves many faces and may be influenced by many factors, we have seen a correlation between the roughness of the dominant BFDH face and conditions of milling needed to obtain such a form. Thus, polymorphs with a dominant smooth surface predominate under NG conditions. The results are very encouraging and provide an accessible method for a priori identification of NG-polymorphs.

\section{Conclusions}

We have explored polymorphic transformations upon milling on four systems of pharmaceutical relevance and have shown how the milling conditions determine the polymorph obtained upon milling to equilibrium. The transformations are reversible as long as the conditions of milling are carefully controlled. Polymorphs obtained by ball mill NG are different to polymorphs obtained under our specific ball mill LAG conditions for these four systems. Crystal sizes in NG experiments are considerably smaller than in LAG-experiments and reach size ranges of $\sim 50 \mathrm{~nm}$. These results, together with some from the literature, were then further studied computationally.

Calculated lattice energies revealed that the polymorphs here obtained by LAG are those with the most stable lattices, i.e. they are the most stable polymorphs when crystals are large. In contrast, the polymorphs by NG are the most stable at the nanoscale, when the crystals are small. Linking surface stabilities with roughness then appeared to be a promising and useful way to identify likely NG-forms. We found that NG-polymorphs are those displaying smooth (smaller roughness) dominant surfaces.

This result provides a practical and easy way to identify NGpolymorphs in known polymorphic systems but also in predicted landscapes. Thus, through the more generally available crystal structure prediction calculations, a polymorphic form landscape may be generated computationally. Of those polymorphs close to the global lattice energy minimum, those with smooth surfaces may be likely candidates to be discovered by ball mill neat grinding.

\section{Conflicts of interest}

There are no conflicts to declare.

\section{Acknowledgements}

AJCC thanks the Royal Society for an Industry Fellowship in Astra Zeneca. We thank C. A. Bland for the mechanical and $P$. Donnelly for the software design of the automation of the grinders for repeat grinding, Richard Nightingale' team 
from the mechanical workshop at the Department of Chemistry (University of Cambridge)for the manufacture of the jars, and Simon A. T. Redfern and the Department of Earth Sciences (university of Cambridge)

Orcid numbers. JKMS 0000-0002-5143-5210

\section{References}

1. A. M. Belenguer, G. I. Lampronti, A. J. Cruz-Cabeza, C. A. Hunter and J. K. M. Sanders, Chemical Science, 2016, 7, 6617-6627.

2. A. M. Belenguer, G. I. Lampronti and J. K. M. Sanders, J. Vis. Exp. , 2018, 131.

3. A. M. Belenguer, G. I. Lampronti, N. De Mitri, M. Driver, C. A. Hunter and J. K. M. Sanders, Journal of the American Chemical Society, 2018, DOI: 10.1021/jacs.8b08549.

4. A. Navrotsky, L. Mazeina and J. Majzlan, Science, 2008, 319, 1635-1638.

5. A. Navrotsky, ChemPhysChem, 2011, 12, 2207-2215.

6. Q. Jiang and M. D. Ward, Chemical Society Reviews, 2014, 43, 2066-2079.

7. A. B. M. Buanz and S. Gaisford, Crystal Growth \& Design, 2017, 17, 1245-1250.

8. B. D. Altheimer, S. Pagola, M. Zeller and M. A. Mehta, Crystal Growth \& Design, 2013, 13, 3447-3453.

9. F. Fischer, A. Heidrich, S. Greiser, S. Benemann, K. Rademann and F. Emmerling, Crystal Growth \& Design, 2016, 16, 1701-1707.

10. J. Linol, T. Morelli, M.-N. Petit and G. Coquerel, Crystal Growth \& Design, 2007, 7, 1608-1611.

11. A. V. Trask, N. Shan, W. D. S. Motherwell, W. Jones, S. Feng, R. B. H. Tan and K. J. Carpenter, Chem. Commun., 2005, 0, 880-882.

12. P. Balaz, M. Achimovicova, M. Balaz, P. Billik, Z. Cherkezova-Zheleva, J. M. Criado, F. Delogu, E. Dutkova, E. Gaffet, F. J. Gotor, R. Kumar, I. Mitov, T. Rojac, M. Senna, A. Streletskii and K. WieczorekCiurowa, Chemical Society Reviews, 2013, 42, 75717637.

13. A. M. Belenguer, G. I. Lampronti, D. J. Wales and J. K. M. Sanders, Journal of the American Chemical Society, 2014, 136, 16156-16166.

14. I. Halasz, S. A. J. Kimber, P. J. Beldon, A. M. Belenguer, F. Adams, V. Honkimäki, R. C. Nightingale, R. E. Dinnebier and T. Friščić, Nat. Protocols, 2013, 8, 17181729.

15. H. Kulla, S. Haferkamp, I. Akhmetova, M. Röllig, C. Maierhofer, K. Rademann and F. Emmerling, Angewandte Chemie International Edition, 2018, 57, 5930-5933.

16. T. Matsumoto, J.-I. Ichikawa, N. Kaneniwa and M. Otsuka, CHEMICAL \& PHARMACEUTICAL BULLETIN, 1988, 36, 1074-1085.

17. M. Descamps, J. F. Willart, E. Dudognon and V. Caron, Journal of Pharmaceutical Sciences, 2007, 96, 13981407.

18. J. F. Willart, N. Descamps, V. Caron, F. Capet, F. Danède and $M$. Descamps, Solid State Communications, 2006, 138, 194-199.
19. Y. Hu, A. Erxleben, B. K. Hodnett, B. Li, P. McArdle, Å. C. Rasmuson and A. G. Ryder, Crystal Growth \& Design, 2013, 13, 3404-3413.

20. D. Hasa and W. Jones, Advanced Drug Delivery Reviews, 2017, 117, 147-161.

21. D. Braga, S. L. Giaffreda, F. Grepioni, M. R. Chierotti, R. Gobetto, G. Palladino and M. Polito, CrystEngComm, 2007, 9, 879-881.

22. D. Braga and F. Grepioni, Chem. Commun., 2005, 29, 3635-3645.

23. A. A. L. Michalchuk, I. A. Tumanov and E. V. Boldyreva, Journal of Materials Science, 2018, 53, 13380-13389.

24. J.-F. Willart, J. Lefebvre, F. Danède, S. Comini, P. Looten and M. Descamps, Solid State Communications, 2005, 135, 519-524.

25. N. Bouvart, R.-M. Palix, S. G. Arkhipov, I. A. Tumanov, A. A. L. Michalchuk and E. V. Boldyreva, CrystEngComm, 2018, 20, 1797-1803.

26. A. Boultif and D. Louer, Journal of Applied Crystallography, 2004, 37, 724-731.

27. W. I. F. David, K. Shankland, J. van de Streek, E. Pidcock, W. D. S. Motherwell and J. C. Cole, Journal of Applied Crystallography, 2006, 39, 910-915.

28. A. A. Coelho, Journal of Applied Crystallography, 2018, 51, 210-218.

29. E. A. Payzant, "Other Topics" in Principles and Applications of Powder Diffraction edited by Clearfield, A, Reibenspies, J. H. and Bhuvanesh N., John Wiley and Sons, Ltd, 2008.

30. D. R. Black, Windover, D., Henins, A., Filliben, J., and Cline, J. P, Powder Diffraction 2011, 26, 155-158.

31. A. A. C. R. W. Cheary, J. P. Cline, J Res Natl Inst Stand Technol, 2004, 109, 1-25.

32. F. Allen, Acta Crystallographica Section B, 2002, 58 , 380-388.

33. C. F. Macrae, I. J. Bruno, J. A. Chisholm, P. R. Edgington, P. McCabe, E. Pidcock, L. Rodriguez-Monge, R. Taylor, J. van de Streek and P. A. Wood, Journal of Applied Crystallography, 2008, 41, 466-470.

34. J. P. Perdew, K. Burke and M. Ernzerhof, Physical Review Letters, 1996, 77, 3865-3868.

35. G. Kresse and D. Joubert, Physical Review B, 1999, 59, 1758-1775.

36. P. E. Blöchl, Physical Review B, 1994, 50, 17953-17979.

37. S. Grimme, Journal of Computational Chemistry, 2006, 27, 1787-1799.

38. G. Kresse and J. Furthmüller, Computational Materials Science, 1996, 6, 15-50.

39. G. Kresse and J. Furthmüller, Physical Review B, 1996 54, 11169-11186.

40. G. Kresse and J. Hafner, Physical Review B, 1993, 47 558-561.

41. G. Kresse and J. Hafner, Physical Review B, 1994, 49, 14251-14269.

42. H. J. Monkhorst and J. D. Pack, Physical Review B, 1976, 13, 5188-5192.

43. J. D. H. Donnay and D. Harker, American Mineralogist, 1937, 22, 446-467.

44. W. H. Ojala and M. C. Etter, Journal of the American Chemical Society, 1992, 114, 10288-10293.

45. M. A. Neumann and M.-A. Perrin, The Journal of Physical Chemistry B, 2005, 109, 15531-15541. 
46. F. Fischer, N. Fendel, S. Greiser, K. Rademann and F. Emmerling, Organic Process Research \& Development, 2017, 21, 655-659.

47. F. Fischer, K.-J. Wenzel, K. Rademann and F. Emmerling, Physical Chemistry Chemical Physics, 2016, 18, 23320-23325.

48. T. Friščić, I. Halasz, P. J. Beldon, A. M. Belenguer, F. Adams, S. A. J. Kimber, V. Honkimäki and R. E. Dinnebier, Nat. Chem., 2013, 5, 66-73.

49. T. Friščić and W. Jones, Crystal Growth \& Design, 2009, 9, 1621-1637.

50. S. L. James, C. J. Adams, C. Bolm, D. Braga, P. Collier, T. Friscic, F. Grepioni, K. D. M. Harris, G. Hyett, W. Jones, A. Krebs, J. Mack, L. Maini, A. G. Orpen, I. P. Parkin, W. C. Shearouse, J. W. Steed and D. C. Waddell, Chemical Society Reviews, 2012, 41, 413-447.

51. H. Kulla, M. Wilke, F. Fischer, M. Röllig, C. Maierhofer and F. Emmerling, Chem. Commun., 2017, 53, 16641667.

52. K. L. Nguyen, T. Friscic, G. M. Day, L. F. Gladden and W. Jones, Nat. Mater., 2007, 6, 206-209.

1 